
\title{
CS Research Square \\ Antibacterial Effects of Oak Fruit, Jaft, and Jaftex Herbal Mouthwash: A Review
}

\section{Maria Cheraghi}

Department of Oral Health and Social Dentristry, School of Dental Medicine,Ahvaz Jundishapur University of Medical Sciences, Ahvaz

\section{Fatemeh Babadi ( $\square$ babadi.fatemeh@yahoo.com )}

Department of Oral and Maxillofacial Medicine, School of Dental Medicine, Ahvaz Jundishapur University of Medical Sciences.

\section{Research article}

Keywords: Oak fruit, Inner husk of oak fruit (Jaft), Jaftex mouthwash, Antibacterial, Microorganism, Antibiotic sensitivity

Posted Date: July 15th, 2019

DOI: https://doi.org/10.21203/rs.2.11341/v1

License: (a) (1) This work is licensed under a Creative Commons Attribution 4.0 International License. Read Full License 


\section{Abstract}

Recently, natural products have been evaluated as a source of antimicrobial agent with efficacies against a variety of microorganisms. The antibacterial activities of the oak fruit,inner husk of oak fruit (Jaft), and Jaftex mouthwash have been studiedin several studies. Thisstudy aimedto review the studies ofthe effects of antibacterial properties of the oak fruit, oak fruit hull (Jaft), and Jaftex mouthwash. Materials and Methods In this review study, relevant articles related to the antimicrobial activity of the oak fruit, inner husk of oak fruit (Jaft), and 'Jaftex mouthwash' were searched from the current digital literature using electronic databases namely, SID, ScienceDirect, PubMed, Google Scholar, Magiran, Web of Science employing the same keywords from 1990 to 2019. Results Oakfruit, inner husk of oak fruit (Jaft), and Jaftex mouthwash have antimicrobial properties against many microorganisms. Discussion and Conclusion Antibacterial properties of oak fruit, inner husk ofoak fruit (Jaft) can be used to reverse the antibiotic sensitivity against pathogenic bacteria. Jaftex is recommended as an antibacterial and antiplaque mouthwash.

\section{Background}

The twenty-first century is called "the century of back to nature and the use of medicinal plants"(1).In recent years, due to concerns about some the safety of synthetic compounds, there has been an increasing interest in the use of natural substances, encouraging more detailed studies on originated substances (2).Medicinal plants containing plant materials such as leaf,root, flower, and seed, are used in the form of extracts and chemical compounds to produce human drugs or veterinary medicines (3).Infectious diseases caused by different microorganisms are very common worldwide (4).Recently,antibiotic drug resistance by pathogenic microorganisms, which has been an increasing problem in the past few decades, has led to the continuous exploration of natural plant products for new antibiotic agents (5). Recently, natural products have been evaluated as a source of the antimicrobial agent with efficacies of a variety of microorganisms (6).The extracts and essential oils of many plants have exerted biological activity, justifying research on traditional medicine focused on the characterization of antimicrobial activity of these plants. Iran, India, Pakistan, and Turkey are examples of countries that have diverse flora and a rich tradition in the use of medicinal plants for antimicrobial applications (7-9).According to the World Health Organization (WHO), $80 \%$ of the world's population uses traditional herbal medicines for the initial treatment of their diseases (10).In the western regions of Iran, people use the extract of different plants such as the extract of the inner layer of oak (Jaft in Persian) and fruit of the oak tree for the treatment of microbial infections $(11,12)$.Iranian oak has covered central, southern and southeast regions in the Zagros Mountains (13).Iranian oak is a large tree of 20 meters inheight, with a large coral crown and belongs to the Fabaceaefamily. Itsleaves are usually monotonous and egg-shaped with a jagged margin. There are massive star-shaped downs on the leaves, and soft and yellow fur downs also coveritsback. Its fruit is pulled like an oval in velvet and cone-shaped white bowl (1).An oak tree fruit called Acron is located in a bowl named Gland. The fruits have different amounts of oily materials, different sugars, amidon, a small amount of quercetin, pentosan and tannin (14).Oak 
fruithas external and internal layers and its internal layer is known as Jaft (15).The color of Jaft turns from yellow to brown after exposure to light due to oxidation $(15,16)$. According to Iranian indigenous information, this plant is traditionally used for problems,such as gastropathy, (17) acute diarrhea inflammation, burns/cuts, (18) and cancers. Like the fruit, Jaftalso has health benefits (19)The antibacterial activities of different parts of oak have been studied in several studies (20-22).Medicinal herbs are particularly valuable in providing community health in both disease treatment and prevention (23).The use of natural products in dentistry has been justified by their popular use, low cost and appropriate antimicrobial, and anti-inflammatory activities (24). The mouth is a perfect environment for colonization and growth of a wide range of microorganisms, especially bacteria (25). Dental plaque is a complex of microbial community found on the surface of teeth, embedded in a matrix of bacteria and salivary origin (26). The bacteria are responsible for 70-80 percent of the plaques (27).Mouthwashes are oral solutions or liquids used to rinse the mouth in order to remove bacteria (28). Chlorhexidine $(\mathrm{CHX})$ is a golden chemical antiplaque, however, it may cause side effects due to the long usage (29).Herbal mouthwashes are more proper than $\mathrm{CHX}$ because they contain organic compounds, which aremore fitted with body physiology, and they have lower toxicity; therefore, they are recommended for people who cannot use chemical mouthwashes (27). Jaftex is a new herbal mouthwash that consistsof Jaft aquatic extract as a base, aquatic extract of Zataria multiflora(Thyme), and Saturej bachtiarica,this herbal mouthwashis prepared scientifically in the Pharmaceutical Plant Growth Center of Ahvaz Jundishapur University of Medical Sciences (30). The antibacterial effects of Jaftex mouthwash have been studied in the few studies $(27,28,30,31)$.

Various studies have been done on the antibacterial properties of oak fruit and Jaft. The importance of this article is that it has reviewed previous studies in order to summarize and compare the findings, and to pose the possibility of creating an organized and comprehensive view of the research carried out in this area in a summarized form; as a result, it provides a new platform for the synthesis of new herbal products, including antibiotics and herbal mouthwashes.

\section{Materials And Methods}

In this review study, relevant articles related to the antimicrobial activity of the oak fruit, Jaft, and 'Jaftex mouthwash' were searched from the current digital literature using electronic databases, namely, $S I D$, ScienceDirect, PubMed, Google Scholar, Magiran, Web of Science, employing the same keywords from 1990 to 2019.This literature was searched using keywords such as antimicrobial, oak fruit, Jaft, Jaftex, mouthwash, microorganism, antibiotic sensitivity in the last 29 years, particularly the recent 10 years.sixteen in-vitro study, and two clinical trials were selected and evaluated.Moreover, the contentsand topics of the antibacterial properties of the Jaftessenceand extract, and Jaftex mouthwash have been selected and collected.

\section{Findings}


In an experimental study conducted byEbrahimi et al., antimicrobial activity of methanolic extract of Iranian oak components against Escherichia coli(E. coli) was investigated.Theyreported that Iranian oak has antibacterial properties, the effect of the extracts on the bacteria is concentration-dependent and the antibacterial effects of different parts of the oak are the same and in most cases, less than antibiotics. They concluded that this antibacterial activity was due to the presence of tannins in the extract (32). Ghaderi et al., also reported that oak tree fruit has antimicrobial properties, and in comparison with gentamicin, kanamycin and tobramycinantibiotics, this plant has a good effect on Staphylococcus aureus (S. aureus), E. coli and Staphylococcus epidermidis (S. epidermidis) bacteria. They concluded that the antimicrobial effects of the oak tree fruit are due to the presence of phenolic compounds (33).

Chahardooli et al., reported that oak extract also has a bactericidal property on micrococcus/uteus, Yersinia enterocolitica, Shigella Dysenteriae, Salmonella typhi, and Citrobacterfreundiii (34). Ebrahimi et al., studied antibacterial effects of the oak fruit extract on S. aureus, S. epidermidisand E. coli bacteria. After observing the antibacterial effects of the extract on bacteria, this property was attributed to phenolic compounds, especially tannins existing in these plants (35).In an experimental study, the antibacterial effects of the oak tree fruits (Quercus persica), collected in different parts of the Zagros Mountains in eastern Iran, against $S$. aureus, Bacillus Sutilis, Klebsiella Pneumoria, and E. coliwere studied by the disc diffusion method. According to the results of this study, Ghilane Gharb extract was the most inhibition zone against $\mathrm{S}$. aureus among the extracts of plants. They concluded that the extract of oak is effective for control of bacteria strains,especially $S$. aureus, and so it could be used as a natural antimicrobial agent (36).In an experimental study, Ebrahimiet al., studied antibacterial andwound-healing effects of methanolic extract of Quercus persicafruits. The extract effect in three concentrations $(25,50,75$ $\mathrm{mg} / \mathrm{ml}$ )on $S$. aureus, $S$. epidermidis, and $E$. coliwas tested using the agar diffusion method and results showed that all of the concentrations were effective in inhibition of bacteria. Also, the extract effect was similar to,or higher than,the tested antibiotics (37). These results suggest that Quercus persica possesses antibacterial compounds.In a study to investigate the biosynthesis of silver nanoparticles using the extract of the oak tree fruit and investigating their antimicrobial activities against agents of nosocomialinfection, Chahardooli et al., reported that the extract of the oak tree fruit has antimicrobial activity against $E$. coli, S. aureus, pseudomonas aeruginosa,and bacillus subtilis (38). In a laboratory study, Panahi et al., investigated the inhibitory effect of the alcoholic extract of the Jaft on Candida albicans. According to them, the highest inhibitory area was seen in $80 \mathrm{gr} / \mathrm{disk}$ and $80 \mathrm{mg} / \mathrm{ml}$ using the disc diffusion method and agar well diffusion, respectively. They concluded that the alcoholic extract of the Jaft contains metabolites with an inhibitory effect on Candida albicans. The antibacterial effect of hydroalcoholic extract of this fruit was due to lavanoidas (11). Karimi Poor fardet al.,carried out a research about antibacterial activities of thymus denaensis, Jaft, and hydroalcoholic extract of green hull pistacia atlantica on listeria monocytogenes. Their study indicates that a hydroalcoholic extract of Jaft has the most antibacterial effect compared with other extracts (39). Roozegar et al., reported that the alcoholic extract of Jaft has an inhibitory effect on anacinetobacter. The highest inhibitory effect of Jaft was in $80 \mathrm{mg} / \mathrm{ml}$ concentration (40).Comparison of the results of the above study shows that most of the research in this field was In-vitro experimental study. The disk-diffusion agar method was used to 
measure the inhibition zone on the tested extract of oak fruit on microorganisms. The tube dilution method was used for determining the minimum inhibitory concentration $(M I C)$ and minimum bacterial concentrations $(M B C)$. In these papers, hydroalcoholic, methanolic and essential oil extracts have been used more than other extracts. The antibacterial effect of oak components has been investigated more against S. aureus, S. mutans, S. epidermidis, S. salivarius bacteriaand E. coli Ebrahimi et al., have conducted the most research on the antibacterial properties of oak. Comparison of the results of their studies shows that oak fruit has the most antimicrobial effect (32). The concentration of $75 \mathrm{mg} / \mathrm{mc}$ of methanolic extract of this fruit has an antibacterial effect more than antibiotics of gentamicin, Tobramycin and Kanamycin (32). One of the findings in their studies, compared with antibiotics the effect of the $75 \mathrm{mg} / \mathrm{mc}$ concentration of hydroalcoholic extract of oak fruit on S. aureus, was similar to gentamicin, lower than that of kanamycin and more than that of tobramycin. Also, the concentration of extract has the same effect as Kanamycin, more than gentamicin and lower than tobramycin on S.epidermis. This effect on E. coli was lower than gentamicin and Kanamycinbut more than tobramycin (35). Paying attention to the above-mentioned can provide new developments in the manufacture of herbal antibiotics made from oak fruit in the future.In a study, Alipur et al., prepared and evaluatedan herbal mouthwash containing oak husk of Quercus brantii and Zataria multiflora. antimicrobial activity of formulation. The results showed that the best formulation with adequate stability was the formulations of the mouthwash containing $0.2 \%$ and $0.5 \%$ tannins. The results also showed antimicrobial activity in formulationsof both types of mouthwash(18). Babadi et al., compared the antibacterial effects of Jaftex with chlorlexidine (CHX) mouthwash on some common oral icroorganisms. They concluded that Jaftex has antibacterial effects on $S$. mutans, $S$. sanguinis and $S$. salivaris, but it is less effective for oral bacteria growth inhibition compared to $\mathrm{CHX}$ (31). It is recommended to be used for plaque inhibition (31). In a study, Babad et al., compared the antibacterial effects of Jaftex herbal mouthwash with Matrica and Persica on S. mutans, S. sanguinis, S. salivaris, and Lactobacillus casei. They reported that Jaftex has a greater inhibitory effect on bacterial growth than Matrica and Persica (27) The results of measuring the effect of MIC and MBC for Jaftex, Matrica and Persica on Streptococcus mutans, Streptococcus sanguinis, Streptococcus salivaris and Lactobacillus casei are reported in Table 1. In an in vivo study, Babadiet al., compared the effect of Jaftex, and chlorhexidine mouthwash onthe oral microorganism.The results of this study showed that the Jaftexmouthwash significantly reduced the number of microorganisms in the mouth, but it had a less antimicrobial effect compared to CHX (30) (Table). In a study, Jahangirnejad et al., investigated the effect of the Jaftex mouthwash on periodontal index compared with chlorhexidine.They noted that Jaftex reduces the amount of plaque and gingival index (41). For the new mouthwash of the Jaftex, two laboratory articles and two clinical trials are available.The comparison of the above studies shows that Jaftex antibacterial effect on oral microorganisms is lower than that of $\mathrm{CHX}$, but is higher than Persica and Matrica herbal mouthwashes (27). The results of clinical trial studies also show that Jaftex reduces the number of salivary microorganisms (30). Jaftex reduced the amount of plaque index and gingival index. Furthermore, Jaftex increased the staining and the intensity of stained area indicators yet the amount and intensity of the staining in the use of $\mathrm{CHXmouthwash} \mathrm{were} \mathrm{more,} \mathrm{and} \mathrm{the} \mathrm{difference} \mathrm{was} \mathrm{not} \mathrm{statistically} \mathrm{significant} \mathrm{(41).}$ 


\section{Discussion}

The profession of dentistry has a lot of charm. However, this profession in the clinical setting also presents risks to dentists and patients (42-48). A review of past studies has shown that oak tree fruit, Jaft, and Jaftex mouthwash have antibacterial properties.Some of the properties ofthe plant extracts leading to antibacterial properties are: 1) The hydrophobic property that cause the extract to penetrate into the bacterial cell membrane lipid and ultimately the death of the bacterium; 2(phenolic materials in this extract containing carvacrol, eugenol and thymol, which interfere with the proton and electrical current of the cell and coagulate the contents of the cell by damaging the cytoplasmic membrane of the bacterial cell:more phenolic substances, more antibacterial effect; 3 )binding the carbonic acid group of the extracts to the cellular proteins and preventing the role of amino acid and decarboxylase, which is more due to the presence of cinnamaldehyde in the extracts (4).Previous studies have shown that increasing the concentration of plant extracts increases their antibacterial effect, which can be attributed to the amount of active ingredient in the extracts, which is higher in fruits than in other parts (32). At high concentrations, the antibacterial effect of the extract was similar with, or even better than, some antibiotics. It is noteworthy that selecting the appropriate method and solvent for extraction is important for obtaining parts with high antibacterial activity and significantly affects the extract's product and its biological activity (32).At high concentrations, the antibacterial effect of the extract was similar with, or even better than, some antibiotics. It is noteworthy that selecting the appropriate method and solvent for extraction is important for obtaining parts with high antibacterial activity and significantly affects the extract's product and its biological activity (32). There are many reports on the antibacterial effect of oak fruit and Jaft due to the presence of phenols, tannins, and proteins in this plant (49-53). Oak is one of the richest fruits in terms of tannin content (54).Polyphenols and tannins are the main substances in the oak tree and are abundant in all parts of Quercus biantii (28). Tannin is one of the most important components of oak trees (14). Plants containing tannins are called astringent (55).Lelerc argued that tannin should be considered one of the most prominent substances in the world of plants (14).Scalbert examinedthe antimicrobial properties of tannins. According to these studies, tannins can be toxic to bacteria, fungi and even viruses (56).According to Lelerc,tannin should be considered as one of the most prominent substances in the world of herbs (14). Scalbert examined the antimicrobial properties of tannins. According to these studies, tannins can be toxic for bacteria, fungi and even viruses (56).The difference in the antimicrobial property of different parts of the plant is due to the presence of the different amounts of tannins in them. Tannin is a common name for a group of molecular polymeric materials with high molecular weight, which is one of the important classes of secondary metabolites in plants (57-58).Antimicrobial activity of tannins is carriedout with different mechanisms, with deposition, microbial proteinsinhibit their growth, as a result, food proteins are not available to them, or play a role through the mechanism of trapping iron, hydrogen bonding, and specific dispersions with vital proteins like enzymes (55-59).Jaftex mouthwash is a hybrid herbal solution of the Jaft as the base of Bakhtiari savory and thyme.Because of the minimum side effects of herbal mouthwash, theycan be recommended for long-term use. On the other hand, the presence of ethanol in commercial mouthwash seems to be problematic due to different reported side effects (28). A review of studies has shown that Jaftex has 
shown antibacterial activity against common oral microorganisms and periodontal indexes in vitro and in vivo conditions (27-41). The antibacterial property of this mouthwash is largely attributed to the extract of Jaft (30).According to a review of the past studies, thyme and Saturej bachtiarica have some antibacterial effects. The antibacterial effects of these two products are attributed to the compounds of their elements. Thymol and carvacro/ have been reported to be one of the most important compounds in thyme and Saturej bachtiarica (60-67).A remarkable point about the effect of herbal extracts on bacteria is that the antibacterial properties of herbal extracts against gram-positive bacteria are more than gramnegativebacteria. Perhaps the limitation of penetration of the extract into the layer is due to the presence of polysaccharide membranes of gram-negative bacteria (65).

\section{Conclusion}

The oak tree fruit, Jaft, and also Jaftex mouthwash have antibacterial properties and are effective against a range of oral bacteria. The use of Jaftex is recommended as an anti-bacterial and anti-plaque mouthwash.

\section{Declaration}

\section{Abbreviation}

Not applicable in this section

- Ethics approval and consent participate: Not applicable

- Consent for publication: Not applicable

- Availability of data and material: Not applicable

Competing interests: There are no competing interests for authors.

- Funding: Not applicable

- Authors' contributions: Dr. Maria Cheraghi, conceived and designed review paper, Search in data base, edit English language, Dr. Fatemeh Babadi: conceived and designed review paper, wrote the paper and mange the project.

- Acknowledgments: Not applicable References

1. Sabeti H. Forests, trees and shrubs of ran. 3nd ed. Yazd University Press Iran. 2003, PP: 576.

2. Ghasemi Pirbalouti A, Hossayni I, Shirmardi HA. Essential oil variation, antioxidant and antibacterial activity of mountain fennel (Zaravschanica membranacea (Boiss) Industrial Crops and products. 2013; 50: 443-448. 
3. Nikbakht A, Kafi M. The history of herbal medicine and medicinal plants in Iran. Proceeding of the 8th international plant-people relationship symposium (IPPS), 2004. Hygo.Japan.

4. Razavi N, Molavi Choobini Z, Salehian-Dehkordi M, Saleh Riyahi S, Salehian- Dehkordi M, Molavi Choobini S.Overview of the antibacterial properties of essential oils and extracts of medicinal plants in Iran. J Shahrekord Univ Med Sci. 2016; 17(Suppl): 41-52.

5. Okunowo WO, Oyedeji O, Afolabi LO, Matanm E. Essential oil of grape fruit (Citrus Paradisi) peels and its antimicrobial activities. Am J Plant Sci. 2013; 4: 1-9.

6. Subasish B, Prashant K, Sandhya Kapoor P, Deepak A, Minal KH, Jitendra L. Evaluation of Antibacterial Activity of Three Selected Fruit Juices on Clinical Endodontic Bacterial Strains. J Pharm Bioallied Sci. 2017; 9 (Suppl 1): S217-S221.

7. Ghasemi Pirbalouti A. Medicinal plants used in Chaharmahal and Bakhtyari districts. Iran. Herba Pol 2009; 55: 69-75.

8. Mahasneh A.M.A, Adel MA, El-Oqlah A.A.B. Antimicrobial activity of extracts of herbal plants used in the traditional medicine of Jordan. Journal of Ethnopharmacology1999; 64: 271-276.

9. Navarro V,Villarreal MI, Rojas G, Lozoya X. Antimicrobial evaluation of some plants used in Mexican traditional medicine for the treatment of infectious disease. Journal of Ethnopharmacology 1996; 53 : 143-147.

10.Vashist H, Jindal A. Antimicrobial activities of medicinal plants- Review. Int J Res Biomed Sci 2012; 3(1): 222-30.

11. Panahi J, Havasian MR, Pakzad I, Davudian A, Jalilian F, Jalilian A. In Vitro Inhibitory Effect of Alcoholic Extract of Inner Stratum of Oak Fruit (Jaft) on candida Albicans. J Pharm Bioallied Sci 2013; 3(1): 5-8.

12.Moore J, Perkins A. Evaluating antimicrobial efficacy and cost of 3 dressings containing silver versus a novel antimicrobial hydrogel impregnated gauze dressing containing Oakin, an oak extract. Adv Skin Wound Care 2010; 23(12): 544-51.

13. Yarmand M.S, Fadavi A, Labbafı Mazrae Shahi M, Sharifi F, Kheiralipur K. Biophysical, biomechanical and bioproximate properties of Iranian oak fruit. Journal of Agricultural Technology 2012; 8(4): 13351342.

14. Motevaselina M, Farahi F. Measurement of Extractive Materials of Quercus infectoria for foodstuff and medicinal value of It. Doctoral thesis. Medical faculty. Tehran University. 1979.

15. Khosravi A.D, Behzad A. Evaluation of the antibacterial activity of the seed hull of Quercus brantii on some gram-negative bacteria. Pak. J. Med. Sci 2006; 22: 429-432. 
16.Mirzaei A, Mirzaei N. Acute and Chronic of Iranian Jaft on Oak Fruit Component. Research Journal of Biological Sciences 2012; 7 (9-12): 350-354.

17. Konig M, Scholz E, Hartmann R, Lehmann R, Rimpler H. Ellagitannins and complex tannins from Quercus petraea bark. J. Nat. Prod 1994; 57: 1411-1415.

18. Khennouf S, Gharzouli S, Amir S, Gharzouli A. Effects of Quercus ilex L. and Punica granatum L polyphenols against ethanol induced gastric damage in rat. Pharmazie 1999; 54: 75-76.

19- Jahanshahi GH,Moattar F, Soltani MR. Evaluation of a herbal medicine in the Treatment of Recurrent Ulcer. Beheshti Univ. Dent. J. 2004; 22(1): 19-25.

20.Basri D.F, Fan S.H. The potential of aqueous and acetone extracts of galls of Quercus infectoria as antibacterial agents. Indian Journal of Pharmacology 2004; 73: 26-29.

21. Ghaderi Ghahfarokhi M, Sadeghi Mahoonak A, Alami M, Khomeiri M, Mamashloo S. Evaluation of Antimicrobial Activity of the Ethanolic Extracts from Q.branti and Q.castaneifolia Fruit Against Some Foodborne Pathogens by Microdilution Method. Food Technology \& Nutrition 2012; 9 (1): 81-95.

22. Nourafcan H, Nasrollahpour M, Bajalan I. Antibacterial Activity of Leaves Extract from Oak (Quercus persica) Against Some Positive and Negative Bacteria. International Journal of Farming and Allied Sciences 2013; 2 (24): 1153-1155.

23. Ghassemi F, Momenzade M, Nagafian M, Kargar Jahromi H. The effect of Oak fruit hushs on liver in Rat(Wistar). Par J Med Sci 2014; 12(3):37-43.

24. Cavalcanti YW, Almeida LFD, Costa MMTM, Padilha WWN. Antimicrobial activity and ph evaluation of calcium associated with natural products. Braz Dent Sci 2010; 13: 49-55.

25. Marcotte H, Lavoie MC. Oral microbial ecology and the role of salivary immunoglobulin A. Microbiol Mol Biol Rev 1998; 62(1): 71-109.

26. Babadi F, Amin M, Ahmadi Behbahani F. Evaluation of the Antibacterial properties of Lactobacillus Acidophilus Metabolites against Oral Plaque Streptococci: An in vitro Study. Journal of Research in Medicinal and Dental Science 2018; 6(5): 198-202.

27. Babadi F, Amin M, Sharafi N, Saki M. Comparison of the Antibacterial Effects of Jaftex Herbal Mouthwash with Matrica and Persica on Streptococcus mutans, Streptococcus sanguinis, Streptococcus salivarius and Lactobacillus casei. Journal of Research in Medicinal and Dental Science 2018; 6(5): 349354.

28.Alipour SH, Dehshahri SH, Afsari A. Preparation and Evaluation of a Herbal Mouthwash Containing Oak Husk of Quercus brantii and Zataria multiflora. Jundishapur Journal of Natural Pharmaceutical Products 2018; 13 (3): e13420. 
29. Sharma R, Hebbal M, Ankola AV, Murugaboopathy V, Shetty SJ. Effect of two herbal mouthwashes on gingival health of school children. J Tradit Complement Med 2014; 4(4): 272-8.

30. Babadi F, Akbarnezhad M, Amin M, Saebi KH. Effect of Jaftex and Chlorhexidine Mouthwashes on Oral Microorganism: A Comparative Study. Journal of Research in Medical and Dental Science 2019;7 (2): 20-24.

31. Babadi E, Bamzadeh Z, Babadi F. Comparison of the Antibacterial Effects of Chlorhexidine Mouth washes with Jaftex Mouth wash on Some Common Oral Microorganisms (An in Vitro Study). WORLD FAMILY MEDICINE 2017; 15 (9): 200-203.

32. Ebrahimi A, Khayami M, Nejati V. Comparison of antimicrobial effect of different parts of Quercus Persica against Escherchia coli 0157:H7. Ofagh-e- Danesh 2012; 18(1): 11-8.

33. Ghaderi Ghahfarokhi M, Sadeghi Mahoonak A, Alami M, Khomeiri M, Mamashloo S. Evaluation of antimicrobial activity of the ethanolic extracts from Q.Branti and Q.Castaneifolia fruit against some foodborne pathogens by microdilution method. J Food Technol Nutr 2012; 9(1): 81-94. 56.

34. Chahardooli M, Khodadadi E. The biosynthesis of silver nanoparticles using oak fruit extract and investigating their anti-microbial activities against nosocomial infection agents. Sci J Ilam Uni Med Sci 2015; 22: S27-33.

35. Ebrahimi A, Khayami M, Nejati V. Evaluation of antimicrobial activity of Hydroalcoholic extract of Iranian Oak fruit in disk diffusion method. Journal of Medicinal Plants 2008; 1(33): 26-8-34.

36. Bajalan I, Javadian M, Zarinkoob S, Dalvand H. Antibacterial Activity of the Extract of Oak (Quercus persica) Fruits. Bull. Env. Pharmacol. Life Sci 2014; 3 (5): 62-65.

37. Ebrahimi A, Khayami M, Nejati V. Evaluation of the Antibacterial and Wound Healing Activity of Quercus persica. Journal of Basic \& Applied Sciences 2012; 8: 118-123.

38. Chahardooli M, Khodadadi E. The Biosynthesis of Silver Nanoparticles using Oak Fruit Extract and Investigating Their Anti-Microbial Activities against Nosocomial Infection Agents. Scientific Journal of Ilam University of Medical Sciences 2013; 22: 27-33.

39. Karimi Poor fard M, Mirzaei A, Kargar M, Khosravani SAM, Mohamadi R. Antibacterial Activities of Thymus Denaensis, Jaft and Hydro-Alcoholic Extract of Green hull Pistacia Atlantica on Listeria Monocytogenes. Armaghane-danesh, Yasuj University of Medical Sciences Journal 2011; 17(1): 68-77.

40. Roozegar MA, Panahi J, Havasian MR, Pakzad I. Studying the inhibitory effect of Alcoholic extract of inner Stratum of Oak fruit (jaft) and hydro alcoholic extract of Summer bulb on Acinetobacter in vitro. International Research Journal of Biological Sciences 2014; 3(6): 63-65. 
41. Jahanghirnejad M, Babadi F, Safikhani E,Ali Hemmati AA, Amiri Y. Comparison of the Effects of Chlorhexidine Mouthwash with Jaftex on Periodontal Index. Indian J Public Health Res Dev 2018; 9:255. 29.

42. Gilavand A. The Comparison of Iranian and Foreign Students' Motivations to Choose Dentistry Field of Study. International Journal of Pediatrics, 2016; 4 (6):1993-2010. doi: 10.22038/ijp.2016.6861

43. Gilavand A. The comparison of the tuition-paid and free tuition dental students' incentives in choosing their feld of study at Ahvaz Jundishapur University of Medical Sciences, Southwest of Iran. Annals of Tropical MedicineandPublic Health. 2017; 10(5): 1254-1259. doi: 10.4103/ATMPH.ATMPH_316_16.

44. Gilavand A, Moezzi M, Gilavand S. Test Anxiety In Dental Students: A Study at the Ahvaz Jundishapur University of Medical Sciences, Iran , Journal of Research in Medical and Dental Science, 2019, 7(1):115120

45. Gilavand A, Shooriabi M. Investigating the Relationship between Mental Health and Academic Achievement of Dental Students of Ahvaz Jundishapur University of Medical Sciences. International Journal of Medical Research \& Health Sciences. 2016; 5(7S): 328-333.

46. Shooriabi M, Gilavand A, Emam SA. Evaluating the Awareness and Performance Ratio of Dental Assistants Working In Dentistry Centers of the City of Ahvaz in Southwest Iran, about Infection Control. . Indo American Journal of harmaceutical Sciences. 2017; 4(9): 2959-2967.

doi.org/10.5281/zenodo.892396

47. Gilavand A., Espidkar F. Evaluating the Academic Status and Job prospect of Dentistry Graduates in Iran. Indo American Journal of Pharmaceutical Sciences, 2018; 05(05): 3520-3524.

doi.org/10.5281/zenodo.1243214

48. Gilavand A, Shooriabi M, Malakootian M. Investigating the Frequency of Occupational Exposure in Dentistry Students of Ahvaz Jundishapur University of Medical Sciences in Southwest of Iran. Asian Journal of Pharmaceutical and Clinical Research, 2018; 11(2): 1637-1642. 297-299.

doi.org/10.22159/ajpcr.2018.v11i2.23191

49. Kaur G, Hamid H, Ali A, Alam M. S., Athar M. Antiinflammatory evaluation of alcoholic extract of galls of Quercus infectoria. Journal of Ethnopharmacology 2004; 90(2-3): 285-292.

50. Sawangjaroen N, SawangjaroenK, Poonpanang P. Effects of Piper longum fruit, Piper sarmentosum root and Quercus infectoria nut gall on caecal amoebiasis in mice. Journal of Ethnopharmacology 2004; 91(2-3): 357-360.

51. Yousef Elahi M, RouzbehanY. Characteriztion of Quercus persica, Quercus infectoria and Quercus libani as ruminant feeds. Animal Feed Science and Technology 2008; 140(1-2): 78-89. 
52. Kaur G, Athar M, Alam M. S. Quercus infectoria galls possess antioxidant activity and abrogates oxidative stress-induced functional alterations in murine macrophages. Chemico-Biological Interactions 2008; 171(3): 272-282.

53. Nabati N. Mojab F, Habibi-Rezaei M, BagherzadehK, AmanlouM, Yousefi B. Large scale screening of commonly used Iranian traditional medicinal plants against urease activity. DARU Journal of Pharmaceutical Sciences 2012; 20:72.

54. Yousef Elahi M, Rouzbehan Y. Characterization of Quercuc persica, Quercus infectoria, Quercus libani as Ruminant feeds. Animal Feed Science Technology 2008; 140: 78-89.

55. Motar MLR, Thomas G, Barbosa Fillo JM. Effects of Anacardium occidental stem bark extract on in vivo inflammatory models. Ethnopharmacol 1985; 95(139-42).

56. Cowan MM. Plant products as Antimicrobial Agents. Clin. Microbial. Rev. 1999; 12(4): 564-82.

57. Nair R, Kalariya T, Chanada S. Antibacterial activity of some plant extracts used in folk medicine. J Herb Pharmacother 2007; 7:191-201.

58. Ravanshad S, Basiri E, Mohammadzadeh M. In vitro evaluation of the antimicrobial effectiveness of Zataria multi囚lorf as an irrigant in infected root canals with Enterococcus faecalis. Shiraz Univ Dent J $2009 ; 10: 92-8$.

59. Scalbert A. Antimicrobial properties of tannin. Phytochem 1991; 30: 3875-83.

60. Safari R, Adel M, Monji H, et al., Evaluation of antibacterial effect of some of the endemic herbal essential oils on Streptococcus iniae in vitro. J Aqu Eco 2015; 4:40-33.

61. Oke F, Aslim B, Ozturk S, et al., Essential oil composition antimicrobial and antioxidant activities of Saturejacuneifolia. Ten Food Chem 2009; 112:874-9.

62. Ghasemipirbalouti A, Rahimi E. Antimicrobial activity of essential oils of three herbs against Listeriamonocytogenes on chicken frankfurters. Actaagric Slov 2010; 95:219-23.

63. Azaz D, Demirci F, Satil F, et al., Antimicrobial activity of some satureja essential oils. Z Naturforsch 2002; 57:817-21.

64. Habibian DS, Gholipour S, Moshtaghi BH, et al., Evaluating antibacterial effects of alcoholic extract of Satureja bactiarica on some foodborne pathogenic bacteria of meat. Vet J 2014; 104:28-37.

65. Mihajilov-Krster T, Radnovic D, Kitic D. Antimicobial activity of satureja L. essential oil against phytopathogenic bacteria Ewinia amylovora. Biol Nyss 2010; 1:95-8.

66. Burt S. Essential oils: their antibacterial properties and potential applications in foods-a review. Int J Food Microbiol 2004; 94(3): 223-53. 


\section{Tables}

\begin{tabular}{|cc|cccc|}
\hline Mouthwash & Concentration & $\begin{array}{c}\text { Lactobacillus } \\
\text { casei }\end{array}$ & $\begin{array}{c}\text { Streptococcus } \\
\text { Salivaris }\end{array}$ & $\begin{array}{c}\text { Streptococcus } \\
\text { Mutans }\end{array}$ & $\begin{array}{c}\text { Streptococcus } \\
\text { Sanguinis }\end{array}$ \\
\hline Jaftex & MIC & 0.0625 & 0.125 & 0.5 & 0.125 \\
& MBC & 0.25 & 0.125 & 0.5 & 0.25 \\
\hline Matrica & MIC & 1 & 0.5 & 0.5 & 1 \\
& MBC & 1 & 0.5 & 0.5 & 1 \\
\hline Persica & MIC & 1 & 1 & 1 & 1 \\
& MBC & 0 & 0 & 0 & 0 \\
\hline
\end{tabular}

Table 1: Results of MIC and MBC measurements for Jaftex, Matrica and Persica mouthwashes (g/ml)

\begin{tabular}{|c|c|c|c|c|c|}
\hline \multirow[t]{2}{*}{ Group } & Before Mouthwash use & \multicolumn{3}{|c|}{$\begin{array}{c}\text { After } \\
\text { Mouthwash use }\end{array}$} & \multirow[t]{2}{*}{ P-value } \\
\hline & Mean & SD & Mean & SD & \\
\hline Jaftex & 164545.45 & 77112.61 & 113636.36 & 3489.18 & 0.005 \\
\hline Chlorhexidine & 180681.82 & 79091,50 & 108500 & 39858.98 & $<0.001$ \\
\hline
\end{tabular}

Table2: Distribution of the Means and Standard deviation for Jaftex and Chlorhexidine mouthwashes on oralmicroorganisms 